\title{
General and Specific Characteristics of a University-School Partnership: Promoting Learning Opportunities for Students with Deafness or Hearing Impairments
}

\author{
Dong-Joong Kim ${ }^{1}$, Yong Joon Park ${ }^{2}$, Jeong-IL $\mathrm{Cho}^{3} \&$ Daesang Kim ${ }^{4}$ \\ ${ }^{1}$ College of Education, Korea University, South Korea \\ ${ }^{2}$ Bayh College of Education, Indiana State University, Terre Haute, IN, USA \\ ${ }^{3}$ College of Education and Public Policy, Indiana University-Purdue University, Fort Wayne, IN, USA \\ ${ }^{4}$ Business and Computer Information Systems, Saint Mary-of-the-Woods College, St Mary of the Woods, IN, \\ USA
}

Correspondence: Dong-Joong Kim, Department of Mathematics Education, Korea University, Seoul 136-701, South Korea. Tel: 82-232-902-331. E-mail: dongjoongkim@korea.ac.kr

Received: October 30, 2012 Accepted: November 14, $2012 \quad$ Online Published: November 20, 2012

doi:10.5539/ies.v6n1p57

URL: http://dx.doi.org/10.5539/ies.v6n1p57

\begin{abstract}
The purpose of this article is to identify six key features involved in the development and enhancement of a university-school partnership and to share insights on how these features can be used to promote richer experiential learning opportunities of both university students and young children with deafness or hearing impairments, eventually resulting in synergistic university-school interactions. The key features are categorized into general characteristics which are applicable to many university-school partnerships (shared goals, availability of funding for a highly successful revamped partnership, and inter-impact mechanisms) and specific characteristics for university partnerships with specialized schools (interdisciplinary collaboration, distinct roles, and expertise resources) in the process of building and implementing university-school partnerships. The key features and their implications for the successful future university-school partnerships are discussed in an educational context.
\end{abstract}

Keywords: characteristics, deafness, hearing impairments, mathematics computer game, university-school partnership

\section{Introduction}

University-community partnerships have been growing in number in many countries including the United States (see Holland, 2001). The value of these partnerships has been affirmed as they can be mutually beneficial for all involved parties. As a means for building social capital, partnerships between universities and communities are especially critical in enriching university student and faculty experiences and addressing community needs (Ramaley, 2001). Community-based research, that is conducted in the process of the university-community partnerships, can benefit both university and community members with richer experiential learning opportunities, deepen faculty interest in community needs, and increase community members' understanding of university missions and activities for the better use of services and education programs provided by universities. Collaborative partnerships between universities and schools deserve particular attention due to their potential in improving student learning (Epstein, 2001). Such partnerships can provide new learning opportunities for children with disabilities who may have a limited access to learning provided by traditional methods.

Most of the research on university-school partnerships, however, focuses more on instruction for typically developing students or teacher training (e.g., Baum, 2000; Bepko \& Payne, 2002; Dewar \& Isaac, 1998; Peel, Peel, \& Baker, 2002; Rakow \& Robinson, 1997; Saito, Imansyah, Kubok, \& Hendayana, 2007; Sconzert, 2001). There has been little research on university-school partnerships geared towards the improvement of learning opportunities for children with disabilities. Therefore, it is necessary to look beyond the typical partnerships and focus on partnerships with specialized schools. The current project recruited a school for young children with deafness or hearing impairments. 
University-school partnerships may differ depending on educational contexts. An enhanced understanding of common and unique characteristics of how universities and schools for the deaf work together in our project may provide insights relevant not only to partnerships with other schools for the deaf, but also to university-school partnerships in general. We narrow the focus to the following specific questions to be answered: How might partnerships between universities and schools for the deaf work together differently from other university-school partnerships? How can optimal relationships between universities and schools for the deaf be developed to maximize benefits to children with deafness or hearing impairments? Are there any important factors especially germane to cooperation between universities and schools for the deaf? How can we increase opportunities for experiential learning for children with deafness or hearing impairments through such cooperation?

The purpose of this article is to identify the key features relevant to a partnership between Indiana State University (ISU) and Indiana School for the Deaf (ISD) through a community engagement project. First, a brief background of this partnership is described. Next, the key features of the university-school partnership are identified in an educational context. Finally, implications are discussed for university-school partnerships in general and particularly for partnerships between a university and a specialized school in improving teaching practices by exploring the unique and specific features of the partnership.

\section{Background}

The No Child Left Behind Act (NCLB) has affected education for students with disabilities. This law requires that all students, including kindergartners with disabilities, should have equal opportunity to access all subject matters and that schools and teachers be accountable for the learning outcomes of their students. The Individuals with Disabilities Education Act (IDEA) requires public schools to develop an Individualized Education Program (IEP) for students with disabilities who are eligible for special education and related services. In developing an effective IEP, the following two key components are to be considered: how students with disabilities can effectively learn and how teachers and other related professionals can help to reach successful learning. With the mission of helping young children with deafness or hearing impairments in learning mathematics, our partnership started with an effort to develop deafness-specific software. In the planning stage of the partnership, the ISD superintendent and teachers expressed their awareness of the need for external supports and concluded that they should collaborate with university professionals to meet their instructional needs to improve students' learning by utilizing computer software.

Indiana School for the Deaf (ISD) is located in the city of Indianapolis, Indiana in the United States and is the only school for the deaf in the State of Indiana. ISD serves more than 300 students with deafness or hearing impairments in grades pre-K through 12. ISD offers a boarding option for students, and about $60 \%$ of the ISD students choose this option. About $50 \%$ of ISD graduates enter a four-year college or university. More than 280 staff members work for ISD as administration, teachers of the deaf, teacher aides, and many other specialized professionals (Krieger, 2007).

Indiana State University (ISU) is a four-year public university located in the city of Terre Haute, Indiana, United States. ISU students and faculty participate in a wide range of community projects and partnerships. In Carnegie's Community-Engagement Classification (Driscoll, 2008), community engagement can be categorized in three areas: (1) only curricular engagement, (2) only outreach and partnerships, and (3) both curricular engagement and outreach and partnerships. During the period of 2006-2008, most institutions (i.e., 112 out of 120) participated in the third category, including ISU, which strongly emphasizes curricular engagement, outreach, and partnerships.

Four faculty members in Early Childhood Education and Mathematics Education at ISU and Educational Technology and Special Education at other universities submitted a grant proposal to ISU in summer 2009 and spring 2010 for a project involving a university-school partnership. The first funded project in summer 2009 emphasized gesture protocols used to identify characteristics of young children with deafness or hearing impairments in learning number concepts with the help of mathematics computer games using paired problem solving, and to develop first-time adapted mathematics computer games. This project provided a meaningful foundation for a strong connection between ISU and ISD. The second funded project in spring 2010 was intended to provide a profile of student performance resulting from the use of the first-time adapted mathematics computer games to analyze a contrasting profile of effects of the same computer games on typically developing students, and to develop the second-time adapted mathematics computer games for young children with deafness or hearing impairments.

Critical elements in establishing an effective partnership were analyzed so as to identify and describe the key features of our partnership. These were elicited from the developmental stages of our collaborative processes. To 
decide what to focus on and include out of all the critical elements, our analytic decision was based on general and specific representative themes found through the collaborative processes. A common theme is related to critical factors for university-school partnerships in general, whereas a specific theme is in connection with critical success factors for partnerships with the schools for the deaf.

\section{Six Key Features of the Current Partnership}

\subsection{Shared Goals}

When an ISU faculty member in Early Childhood Education initially observed the preschool classrooms at ISD on February 10, 2009, he noticed the potential benefits of mathematics computer games for learning number concepts with the assistance of visualization for young children with deafness or hearing impairments. The goal of improving student learning opportunities with developmentally appropriate technology was shared by the ISD superintendent. In a letter of agreement, the ISD superintendent clearly stated that "ISD has been interested in obtaining developmentally appropriate technology tools for kindergartners who are deaf or hard-of-hearing" for experiential learning. In fall 2009, the partnership launched with a vision to improve the mathematical learning of young children with deafness or hearing impairments through a collaborative partnership. This shared vision and dedication in the educational partnership was of great importance in the delivery of appropriate technology in improving student learning.

\subsection{Interdisciplinary Collaboration}

The degree to which any university-school partnership can achieve its goals can be affected by the capacity of each university professional to effectively address the school's needs. Therefore, identification of those professionals who are willing to contribute to the partnership and who have expertise in the relevant field is a significant factor in the success of the partnership. Professionals in four disciplines (Early Childhood Education, Mathematics, Educational Technology, and Special Education) were recruited to prepare and execute all aspects of the current partnership, develop a provisional framework for the current partnership, and investigate characteristics of young children with deafness or hearing impairments in learning numbers through interdisciplinary collaboration. These four professionals brought in substantial experience and knowledge in the process of conceptualization of issues related to the educational partnership. Interdisciplinary collaboration is a challenging development, but proved to be a key factor in the success of the current partnership between ISU and ISD.

\subsection{Distinct Roles}

Setting out the distinct roles of all involved parties (e.g., university and school faculty and staff) to advance a vision towards shared goals entails a considerable effort, especially in assigning appropriate roles to each party. In the dynamics of a university-school relationship, a well-balanced power relation among partnership members is a key factor in improving the quality of the outcome. Developing a clear understanding of the roles of each party is the first step for the power balance. During the current project, two distinct roles were identified: project planning at ISU and project implementation at ISD. University researchers established the framework of the project and developed ways to cooperate with ISD administrators and teachers to identify each other's distinct roles. ISD provided sponsorship and direction for pursuing various aspects of the project within the school context. Since American Sign Language (ASL) is the primary language among ISD teachers and students, ISD provided leadership to enable all parties to effectively communicate with each other. As a result, both parties had defined roles and were accountable either to plan or to implement the project in the school context.

\subsection{Expertise Resources}

Professional knowledge, however, could not be utilized effectively without context-dependent expertise resources. In our partnership, the knowledge of school teachers at ISD who were familiar with deaf culture, the unique learning styles of their young students, and the infrastructure of the school were at the heart of expertise resources. For instance, an ASL interpreter, who was also a classroom teacher at ISD, supported the research team for data collection and analysis. He also assisted university researchers to understand similarities and differences between children with and without deafness or hearing impairments in their learning habits when using computer mathematics games. The support of the ISD superintendent enabled university investigators to set up the research equipment (e.g., computers) in the school library for data collection at ISD during fall 2009. This university-school partnership would have been impossible without the valuable supports from the school teachers and administrators at ISD. 


\subsection{Availability of Funding for a Highly Successful Revamped Partnership}

Funding was a critical issue for the projects. Funding can bring a university and school together and provide social capital to address school needs and establish effective professional development strategies that respond to the changing needs of the school. Our project "No kindergartners with deafness left behind learning early math," funded by the Center for Public Service and Community Engagement at ISU, served as a foundation for our continuous partnership by covering start-up costs. Funding from the Blumberg Center at ISU further established a strong foundation for the successful partnership. Availability of funding is critical in developing a highly successful revamped partnership in a step by step manner.

\subsection{Inter-impact Mechanisms of the Partnership}

University professionals learned the differences in cultures and learning experiences that young children with deafness or hearing impairments experience and disseminated that information to faculty, students, and the public at an ISU conference. Our presentation influenced the birth of the first ISU American Sign Language Club, "Signing Sycamores," which is dedicated to increase the awareness of ASL and the deaf community. As of now, the club has 17 ISU student members and holds weekly meetings for approximately one hour to learn basic signing skills such as the ASL alphabet, ASL in popular songs, and conversational signs. They plan to purchase up-to-date ASL textbooks for all members, take a field trip to ISD, and invite the Deaf Theatre to ISU. A long-term goal of Signing Sycamores is to establish ASL classes at ISU to meet Foreign Language requirements.

Our partnership suggests that university-school partnerships can move beyond the challenge of meeting the school's educational goals. University student engagement in the current partnership transformed the original goal of ISD student learning into a broader goal that encompasses learning opportunities for ISU students and raises public awareness of deaf cultures. In an effective knowledge dissemination process, universities gain benefits associated with community engagement, especially from experiential learning opportunities not only for university and school members, but also for the people in the community.

\section{Discussion and Implication for University-school Partnerships}

Six key features were identified. In this section, we discuss implications of the key features and categorized them into general characteristics (shared goals, availability of funding for a highly successful revamped partnership, and inter-impact mechanisms) and specific characteristics (interdisciplinary collaboration, distinct roles, and expertise resources).

\subsection{General Characteristics}

The first step in developing successful university-school partnerships is for both partners to develop a clear vision that incorporates shared goals. Our partnership has been successful because the shared goal (improving the mathematics learning of young children with deafness or hearing impairments using technology) was clear from the beginning and received strong and unanimous support from school administrators and teachers. The second component is funding, including internal and external support. We were able to successfully secure funding granted by two ISU programs. Finally, regardless of the type of school, inter-impact mechanisms can be a promising component of a successful university-school partnership. A partnership needs to be bidirectional rather than unidirectional to offer mutual benefits for all partnership members (Ramaley, 2001). Our partnership influenced the formation of a new university student club in the dissemination process and promoted ISU students to participate and experience learning of deaf culture and ASL.

\subsection{Specific Characteristics}

The first specific and necessary component in the development of partnerships with specialized schools is inter-disciplinary collaboration (Mullis \& Ghazvini, 1999). Such collaboration is especially important for a partnership aimed at assisting students with disabilities, as it can bring in content expertise as well as expertise in special modifications. For an efficient partnership with specialized schools, university administrators need to encourage faculty members' collaborative and inter-disciplinary interactions without hierarchical empowerment (Prins, 2006; Shefner \& Cobb, 2002).

Continuous and frequent collaboration among faculty members in multiple disciplines was a key factor in the successful partnership. Because faculty members from three universities were involved in the project, several different means of communication were used, including e-mails with attachments, video-conferences using Skype, and word processing software with "track changes" function. Constant communication was the result of a commitment to a shared goal, understanding of each participant's distinct role, and skills in collaboration. In order to continue the current partnership and for further improvement, multiple actions should be taken, such as constant search for better means of communication, constant reminder of the shared goal through regular 
documenting and briefing of the current status, and continuous commitment to and respect for the distinct role of each university faculty participant.

The second specific component in the development of partnerships with specialized schools is distinct roles. A critical issue is how to establish an appropriate power balance between professionals in the university and in the school and determine how they should communicate with one another (Litwak \& Meyer, 1974). Effective communication between universities and schools should be achieved to accommodate a collaborative working relationship. Due to several unique needs of our partnership (e.g., translation of ASL, specialized knowledge of deaf students, and deaf culture), distinct roles of ISD members were indispensable in facilitating a lasting, successful partnership with university faculty and ISD participants.

Finally, specialized knowledge of students with disabilities is essential in meeting their educational needs. The need for context-dependent knowledge in successful partnerships with specialized schools gives further validation to the third component, expertise resources. For example, in our project, we needed to consider paired interview methods rather than individual interview methods due to the relatively dominant preference for collaboration by young children with deafness or hearing impairments in order to achieve our shared goal of improving learning opportunities for them (see also Lang, Stinson, Kavanagh, Liu, \& Basile, 1999).

\section{Conclusion}

This educational partnership is a collaborative effort among university investigators and deaf school partners. In the process of building and implementing the partnership, we identified three general characteristics which can be applicable to many university-school partnerships and three specific features for university partnerships with specialized schools. We hope that this partnership can set a good example of how to work strategically for other potential university-school partnerships, especially for those partnerships specifically designed around specialized schools.

\section{References}

Baum, H. (2000). Fantasies and realities of university-community partnerships. Journal of Planning Education and Research, 20(2), 234-246.

Bepko, G. L., \& Payne, S. M. (2002). Full-service schools: Involving the urban university in school improvement and community redevelopment. Metropolitan Universities, 13(4), 75-87.

Dewar, M. E., \& Isaac, C. B. (1998). Learning from difference: The potentially transforming experience of community-university collaborations. Journal of Planning Education and Research, 17(4), 334-347.

Driscoll, A. (2008). Carnegie's community-engagement classification: Intentions and insights. Change: The Magazine of Higher Learning, 40(1), 38-41.

Epstein, J. (2001). School, family and community partnership: Preparing educators and improving schools. Boulder, Colorado: Westview Press.

Holland, B. (2001). Toward a definition and characterization of the engaged campus: Six cases. Metropolitan Universities, 12(3), 20-29.

Krieger, J. (2007). Indiana school for the deaf: 3-Year Technology plan. Retrieved from http://www.docstoc.com/docs/124236983/Indiana-School-for-the-Deaf-3Year-Technology-Plan-July-1_-20 08

Lang, H., Stinson, M., Kavanagh, F., Liu, Y., \& Basile, M. (1999). Learning styles of deaf college students and instructors' teaching emphases. Journal of Deaf Studies and Deaf Education, 4(1), 16-27.

Litwak, E., \& Meyer, H. J. (1974). School, family and neighborhood: The theory and practice of school-community relations. New York: Columbia University Press.

Mullis, R. L., \& Ghazvini, A. S. (1999). Improving rural child care: A community-university partnership. In T. R. Chibucos \& R. M. Lerner (Eds.), Serving children and families through community-university partnerships: Success stories (pp. 59-64). Boston: Kluwer Academic Publishers.

Peel, H. A., Peel, B. B., \& Baker, M. B. (2002). School/university partnership: A viable model. The international Journal of Educational Management, 16(6/7), 319-326.

Prins, E. (2006). Individual roles and approaches to public engagement in a community-university partnership in a rural California town. Journal of Research in Rural Education, 21(7), 1-15. 
Rakow, S. J., \& Robinson, L. W. (1997). Public-school/university partnerships. The Education Digest, 63(3), 64-69.

Ramaley, J. (2001). Why do we engage in engagement? Metropolitan Universities, 12(3), 13-19.

Saito, E., Imansyah, H., Kubok, I., \& Hendayana, S. (2007). A study of the partnership between schools and universities to improve science and mathematics education in Indonesia. International Journal of Educational Development, 27(2), 194-204.

Sconzert, K. (2001). Warming up to the schools? Connecting universities with teaching practice in Chicago. Metropolitan Universities, 12(4), 116-149.

Shefner, J., \& Cobb, D. (2002). Hierarchy and partnership in New Orleans. Qualitative Sociology, 25(2), 273-297. 